\title{
Paraplegia
}

\section{Investigation of the Afferent Nerves of the Lower Urinary Tract in Patients with 'Complete' and 'Incomplete' Spinal Cord Injury}

\author{
J. J. Wyndaele, MD \\ ${ }^{1}$ Centre for Urodynamics and Urological Reeducation, P6, University Hospital, \\ 185 De Pintelaan, B-9000 Gent, Belgium.
}

\section{Summary}

In 52 patients with a post-traumatic spinal cord lesion, both proprioception and exteroception in the lower urinary tract were investigated by determination of filling perception and with sensory threshold measurement towards electrical stimulation. Patients with incomplete lesions had one or both types of perception.

Of the 42 patients, with a lesion diagnosed clinically as complete, 15 perceived bladder filling, electrical stimulation or both stimuli, indicating the existence of a nervous afferent pathway between the lower urinary tract and the cerebral cortex.

Key words: Neuropathic bladder; Spinal cord injury; Afferent innervation.

The evolution after spinal cord injury (SCI) depends greatly on the completeness or incompleteness of the medullary lesion. ${ }^{1}$

While a 10 years life expectancy has been found in 75 to $80 \%$ of complete tetraplegics surviving the first 3 months post-injury, the same prognosis was ascertained in $90 \%$ of those with an incomplete lesion. ${ }^{2,3}$ In paraplegics a similar difference has been seen. Prognosis, however, also depends on age, ${ }^{4}$ level of injury, ${ }^{5}$ and sex. ${ }^{6}$

Medical treatment, rehabilitation and its outcome are influenced considerably by the extent of the lesion. Its impact on the urological history has been repeatedly described. ${ }^{7,8}$

The diagnosis of completeness of a spinal lesion can be made clinically ${ }^{9}, 10$ and/or with electrodiagnostic tests. ${ }^{11}$

The management of the neuropathic bladder is very important. ${ }^{12}$ Urological related complications are still amongst the leading causes of premature death after SCI. ${ }^{13}$

Urodynamic investigation is mostly needed to provide a clear urological diagnosis. ${ }^{14}$

In such urodynamic investigation, the main interest usually concerns motor 
function evaluation. ${ }^{15}$ Few publications deal with the sensory function of the lower urinary tract, though the afferent innervation is of the upmost importance for motor function. ${ }^{16,17}$

Information about the afferent innervation of the lower urinary tract after SCI can also be important from a pathophysiological point of view, as the sensory pathway travels practically the entire length of the central nervous system. ${ }^{18}$

In this study we give the results of the investigations of the lower urinary tract sensation performed in a group of SCI patients with a 'complete' or an 'incomplete' lesion.

\section{Methods}

During an 8 months period, 52 consecutive patients with a SC lesion, all out of the phase of spinal shock, who came for urodynamic investigation had the sensation of the lower urinary tract investigated by two methods:

1. In the 48 patients, during a medium fill $(30 \mathrm{ml} / \mathrm{min})$ cystometry, the different subjective perceptions (first sensation, desire to micturate, sensation of full bladder) were noted. Patients were in the supine position on a Hydrajust uroradiological table. Bladder filling was performed through a urethral catheter 8 French at a constant flow with a JTL RM302 pump.

A filling solution of $700 \mathrm{ml}$ sterile water and $200 \mathrm{ml}$ Urografine $76 \%$ (Schering) was used at room temperature. The filling was stopped when full bladder sensation occurred or in the case of absent sensation at $600 \mathrm{ml}$. Only a local specific perception was accepted as a sign of bladder sensation. ${ }^{19}$ When perception occurred the volume of the fluid in the bladder was noted.

2. In 33 patients, the sensitivity threshold of bladder and urethra was determined with constant current electrical stimulation. A catheter with 2 ring electrodes $(6 \mathrm{~cm}$ apart), was introduced into the empty bladder or urethra. Thresholds were determined with constant current stimulation (Dimed, Belgium) with square wave impulses of $0.5 \mathrm{msec}$ length, $10 \mathrm{msec}$ interval. The amplitude was gradually increased from 0 to $25 \mathrm{~mA}$ until perception occurred. All measurements were done at least three times. A maximum difference of $1.25 \mathrm{~mA}$ between thresholds was accepted for reproducibility.

During the same urodynamic investigation a clinical neurological examination was performed to confirm the neurological diagnosis to define the extent and completeness of the lesion. The existence of voluntary motor function and/or persisting sensation below a medullary level was used.

\section{Results}

In all patients the clinical neurological examination confirmed the previous findings suggesting completeness or incompleteness of the SC lesion.

Nine patients with an incomplete lesion had one or more perceptions during bladder filling. In 7 of these, electrical sensory threshold was preserved in at least one location of the lower urinary tract (Table I).

The results in the 42 patients with a complete lesion are given in Table II. Fifteen had some preserved sensation. Their data are given in detail in Table III.

In 1 patient with an 'uncomplete lesion' no reliable results could be obtained. 
Table I Results of investigation of lower urinary tract sensation in 9 patients with incomplete SCI

\begin{tabular}{lcccccc}
\hline & & \multicolumn{3}{c}{ Clinical perception } & \multicolumn{2}{c}{$\begin{array}{c}\text { Electrical threshold } \\
(\mathrm{mA})\end{array}$} \\
$\begin{array}{l}\text { Year } \\
\text { SC injury }\end{array}$ & $\begin{array}{l}\text { Level } \\
\text { lesion }\end{array}$ & FS & MS & BS & Bladder & Urethra \\
\hline 1984 & & & & & \\
1978 & L1 & - & 50 & 100 & $15 \cdot 75$ & $8 \cdot 25$ \\
1978 & L1 & - & 250 & 300 & ND & ND \\
1988 & D6 & 190 & 500 & - & $8 \cdot 5$ & $6 \cdot 75$ \\
1985 & D2 & 300 & - & 560 & 20 & $>25$ \\
1987 & C8 & 120 & 350 & - & 12 & $2 \cdot 5$ \\
1987 & D4 & - & - & 480 & ND & $6 \cdot 5$ \\
1985 & C6 & 150 & - & 400 & ND & ND \\
1987 & L4 & - & - & 520 & ND & $4 \cdot 5$ \\
& C5 & - & - & 555 & $>25$ & $9 \cdot 25$
\end{tabular}

$\mathrm{ND}=$ not done; $\mathrm{C}=$ cervical; $\mathrm{D}=$ thoracic; $\mathrm{L}=$ lumbar; $\mathrm{FS}=$ first sensation; $\mathrm{MS}=$ desire to micturate; $\mathrm{BS}=$ full bladder sensation.

Table II Outcome of investigation of sensation in lower urinary tract in patients with 'complete' spinal cord lesion

\begin{tabular}{lcccc}
\hline & \multicolumn{4}{c}{ Electrical sensation } \\
& None & Present & Absent & Not done \\
Filling perception present & 10 & 4 & 4 & 2 \\
Filling perception absent & 28 & 6 & 9 & 13 \\
Filling perception not done & 4 & - & 2 & 2 \\
\hline
\end{tabular}

Table III Results of lower urinary tract sensation in 15 patients with 'complete' SCI and some preserved sensation

\begin{tabular}{lcccccc}
\hline & \multicolumn{9}{c}{ Clinical perception } & \multicolumn{2}{c}{$\begin{array}{c}\text { Electrical threshold } \\
(\mathbf{m A})\end{array}$} \\
Year & Level & FS & MS & BS & Bladder & Urethra \\
SC injury & lesion & & & & & \\
- & D12 & - & 220 & 260 & $>25$ & $>25$ \\
1988 & L1 & - & 500 & - & $>25$ & $>25$ \\
1988 & D11 & - & 350 & - & $>25$ & 4 \\
1985 & L1 & - & 350 & - & 11 & $1 \cdot 75$ \\
1965 & L4 & - & 520 & - & $8 \cdot 25$ & $9 \cdot 25$ \\
1981 & D10 & ND & ND & ND & $>25$ & $16 \cdot 25$ \\
1984 & D9 & - & 500 & -- & $>25$ & $>25$ \\
1988 & D4 & - & 333 & - & ND & ND \\
1988 & D12 & - & 400 & - & $>25$ & $>25$ \\
1988 & D11 & 280 & - & 300 & $5 \cdot 75$ & $>25$ \\
1987 & D3 & - & 240 & 300 & ND & ND \\
1983 & L4 & - & - & 340 & $>25$ & 21 \\
1985 & C5 & - & 180 & - & $>25$ & $15 \cdot 5$ \\
1987 & L1 & 250 & 300 & - & $>25$ & $12 \cdot 5$ \\
1976 & Cl & - & 350 & - & $3 \cdot 25$ & $2 \cdot 25$ \\
1988 & & & & - & & \\
\hline
\end{tabular}

$\mathrm{ND}=$ not done; $\mathrm{FS}=$ first sensation; $\mathrm{MS}=$ desire to micturate; $\mathrm{BS}=$ full bladder sensation. 


\section{Discussion}

In almost all patients with an incomplete lesion and in 15 of 42 patients with a complete lesion, the existence of an afferent nerve pathway from the bladder to the cerebral cortex was demonstrated.

The perceptions during bladder filling are elicited by proprioceptive stimuli on specific receptors in bladder wall, urethra and pelvic floor. ${ }^{20}$ The sensory potentials run through the hypogastric, pelvic and pudendal nerves. ${ }^{21}$

Three different sensations have been described during cystometric bladder filling: first sensation, desire to micturate, and full bladder sensation. ${ }^{22}$

The investigation of exteroceptive sensation in the lower urinary tract with constant current electrical stimulation was shown to give reproducible results. It has been used to determine sensation in the bladder and the urethra. ${ }^{23,24}$

Our data show that even in the presence of a clinically apparent complete SCI, sensory nerves from the lower urinary tract, for proprioception, exteroception or both may be preserved. Of the patients with complete SCI, in whom such nerve pathways were found, the majority had a lower thoracic or a lumbar lesion. In these patients, bladder sensation may be preserved through the hypogastric nerves.

The therapeutic usefullness of intact proprioception seems more evident than the preservation of exteroceptive nerves. Though the physiological role of exteroception is somewhat doubted, ${ }^{25}$ findings of Mahony et al. (1977), show that exteroceptive stimuli from the bladder wall exert control of bladder filling while those from the urethra have a powerful facilitating action on the micturition reflex.

In a previous study, ${ }^{15}$ we demonstrated a good correlation between the clinical neurological investigation and the functional outcome of different parts of the lower urinary tract in $93 \%$ of 108 patients.

Our study shows that such a correlation does not exist between clinical neurological data and the sensory function of the lower urinary tract in SCI patients. Specific tests should be done to gain information on this important urological function.

\section{References}

1. Maury M. Le pronostic. In: Maury M, ed. La Paraplégie. Maury Flammarion Médecine-Sciences, Paris, 1981 Ch 10, p. 146.

2. Bombart M, Senegas J, Barouk L. Le traitement d'urgences des tetraplégiques traumatiques. Ann Méd Phys 1971: 14:390-399.

3. Girard R, Tricot A. Durée de vie et Causes de Mortalité. In: Maury M, ed. La paraplégie. Flammarion Médecine-Sciences, Paris, 1981: Ch 47, p. 622.

4. Watson N. Patterns of the SCI in the elderly. Paraplegia 1976: 14:36-40.

5. Mesard L, Carmody A, Mannarino E, Ruge D. Survival after SC trauma. Arch Neurol 1978: 35:78-92.

6. Kraus JF, Franti C, Riggins R, Borhani N. Survival among persons sustaining acute SCI. 104e Ann Publ Health Assoc Meeting, Miami Beach, 1976.

7. Bors E, Comarr A. Neurological Urology. S. Karger, Basel. 1971: Ch 6, p. 181.

8. Lamid S. Longterm followup of SCI patients with vesicoureteral reflux. Paraplegia 1988: 26:27-34.

9. Lacert P, Maury M. L'examen Neurologique au Stade Séquellaire. In: Maury M, ed. La papaplégie. Flammarion Médecine-Sciences, Paris, 1981: Ch 11, p. 151.

10. Bedbrook GM. The care and management of SCI. Springer Verlag, New York, 1981: p. 13.

11. Glick M, Haldeman S, Meshkinpour $H$. The neurovisceral and electrodiagnostic evaluation of patients with thoracic SCI. Paraplegia 1986: 24:129-137.

12. Hackler RH. A 25 year prospective mortality study in the SCI patient, comparison with the long-term living paraplegic. J Urol 1989: 117:486-488. 
13. Warren JW, Muchie H Jr., Bergquist EJ, Hoope JM. Sequelae and management of urinary infection in the patients requiring chronic catherisation. J Urol 1981: 125:1-8.

14. Wyndaele JJ. Urology in SCI patients. Paraplegia 1987: 25:267-269.

15. Wyndaele JJ. A critical review of urodynamic investigation in SCI patients. Paraplegia 1984: 22:138-144.

16. Goody W. Sensation and volition. Brain 1949: 72:313-339.

17. Mahony DT, Laferte RO, Blais DJ. Integral storage and voiding reflexes. Urology 1977: 9:95-106.

18. Kuru M. Nervous control of micturition. Physiol Rev 1965: 45:425-494.

19. Wyndaele JJ. A clinical study on the different sensations during bladder filling. J Urol 1990: (submitted).

20. Fletcher TF, Bradley WE. Neuro-anatomy of the bladder-urethra. J Urol 1978: 119:153-160.

21. Lose G, Andersen JT. Clinical pharmacology of the lower urinary tract. Eur Urol 1986: 12:1-11.

22. George NJR, Dixon JS. Normal Sensation of the Lower Urinary Tract. In: George N, Gosling J, eds. Sensory Disorders of the Bladder and Urethra. Springer Verlag, Berlin, 1986: Ch 2, p. 7.

23. Frimodt-Möller C. A new method for quantitative evaluation of bladder sensibility. Scand J Urol Nephrol 1972: 6: Suppl. 15:135-142.

24. Kiesswetter H. Mucosal sensory threshold of urinary bladder and urethra measured electrically. Urol Int 1977: 32:437-448.

25. Mundy AR. Clinical Physiology of the Bladder, Urethra and Pelvic Floor. In: Mundy AR, et al., eds. Urodynamics--Principles, Practice and Application. Churchill Livingstone, New York, 1984: p. 14. 